\title{
Tag Return Estimation of Annual and Semiannual Survival Rates of Adult Female Blue Crabs
}

\author{
Debra M. Lambert, John M. Hoenig,* and Romuald N. Lipcius \\ Virginia Institute of Marine Science, The College of William and Mary, \\ 1208 Greate Road, Gloucester Point, Virginia 23062-1346, USA
}

\begin{abstract}
Stock status of the blue crab Callinectes sapidus in Chesapeake Bay is determined by comparing current estimates of fishing mortality with biological reference points. Given the recent focus on blue crab conservation, there is a need to obtain reliable estimates of survival to compare with the biological reference points. A tagging program was initiated on the terminally molted, mature female component of the Chesapeake Bay blue crab stock to estimate annual and semiannual survival rates. Crabs were obtained from fishery-independent research surveys throughout the bay and were measured, tagged, and released on-site. Tagging was conducted twice per year (winter and summer) from November 2001 to March 2005. Annual survival and tag recovery rates were estimated independently for the winter and summer tagging data using Brownie models. The two independent estimates of annual survival based on winter tagging (mean $\pm \mathrm{SE}=$ $0.081 \pm 0.031)$ and summer tagging $(0.080 \pm 0.024)$ data were virtually identical and low. The estimated tag recovery rate was $24 \%$ based on winter tagging data and $17 \%$ based on summer tagging data. The estimated monthly survival rate during winter (mean $\pm \mathrm{SE}=0.868 \pm 0.016$ ) was higher than that during summer $(0.748 \pm 0.019)$. The low estimates of annual survival are consistent with (1) historical estimates of the percentage of age- 2 and older females in the winter dredge fishery, and (2) recent estimates of exploitation rate obtained from the ratio of catch to initial abundance. These findings indicate that survival rates of mature female blue crabs in Chesapeake Bay have remained extremely low during a period of depressed abundance, which may be preventing stock recovery. Moreover, this study represents one of the few to derive experimental Brownie model estimates of semiannual survival of an invertebrate species subject to a continuous fishery.
\end{abstract}

The fishery for blue crabs Callinectes sapidus is one of the most important commercial fisheries in Chesapeake Bay and produces the highest landings of blue crabs in the United States (Miller et al. 2005). The 2002-2004 average annual commercial landings in the Bay (24,500 metric tons) were $26 \%$ below the longterm (1968-2004) average landings of 33,100 metric tons (CBSAC 2005). The Chesapeake Bay stock experienced a period of overfishing from 1998 to 2002 (Miller et al. 2005), which has resulted in belowaverage abundances, and the spawning stock has experienced an $84 \%$ decline in biomass relative to levels in the late 1980s (Lipcius and Stockhausen 2002).

In 2001, the Bi-state Blue Crab Advisory Committee (BBCAC) of the Chesapeake Bay Commission recommended that fisheries management agencies (Potomac River Fisheries Commission, Maryland Department of Natural Resources [MDNR], and Virginia Marine Resources Commission) adopt a fishing mortality threshold (i.e., overfishing biological reference point) and fishing mortality target that preserve a minimum of

* Corresponding author: hoenig@vims.edu

Received December 17, 2005; accepted July 12, 2006 Published online November 9, 2006
$10 \%\left(F_{10 \%}=1.0\right)$ and $20 \%\left(F_{20 \%}=0.7\right)$ of spawning potential, respectively, and a biomass threshold (i.e., overfished biological reference point) equivalent to the lowest recorded stock abundance (BBCAC 2001). Since 2001, the status of the Chesapeake Bay blue crab stock has been determined by comparing estimates of fishing mortality and abundance to the biological reference points. More recently, however, the blue crab stock assessment has adopted an overfishing reference point based on exploitation rate (Miller et al. 2005), while the overfished reference point remains the same. Further refinement includes the estimation of genderspecific reference points, which are currently under evaluation. All regulatory authorities have taken actions since 2001 to reduce fishing mortality and increase stock abundance.

Blue crab stock assessment has been hampered by incomplete catch and effort statistics and uncertainty over maximum age and natural mortality rate (Rugolo et al. 1998). The lack of a suitable method for aging crabs largely rules out the option of using age-based methods to estimate total mortality. Until recently, instantaneous mortality rates $(Z)$ have been assessed from length-frequency distributions (Rugolo et al. 1998) using a model that is heavily dependent on assumptions of equilibrium conditions, known growth 
rates, and non-size-selective harvesting. Recently, there has been a switch in methodology to estimates of exploitation rate $(u)$ based on comparing total catch during the year with estimates of abundance at the beginning of the year of legal size animals and animals that will become legal size during the year. Abundances are determined from the baywide winter dredge survey; relative abundance (crabs $/ \mathrm{m}^{2}$ ) is converted to an estimate of absolute abundance by dividing by the gear efficiency and then extrapolating to the total survey area (Sharov et al. 2003). The total annual catch is based on commercial landings data that is converted from weight to number of crabs. The estimates of exploitation rate ( $u=$ catch/initial abundance) are then converted into estimates of instantaneous fishing mortality rate $(F)$ by assuming a value for the natural mortality rate $(M)$ and a type II (continuous) fishery. That is, Sharov et al. (2003) solved the following equation iteratively for $F$ :

$$
u=\left(\frac{F}{F+M}\right) \times\left(1-e^{-(F+M)}\right)
$$

Sharov et al. (2003) used the value of 0.375 per year for $M$, in line with the value of $M$ used in the previous Chesapeake Bay blue crab stock assessment (Rugolo et al. 1998). Estimates of fishing mortality obtained from this method are compared with target and threshold values to determine if overfishing is occurring.

The new methodology is dependent on estimates of gear efficiency, natural mortality rate, and total catch. The Chesapeake Bay Stock Assessment Committee has endorsed the replacement of the length-based method with the exploitation rate method for the estimation of $F$. Although the exploitation rate method appears the most appropriate, the natural mortality rate remains poorly known and controversial. The most recent stock assessment concluded that a value for $M$ of 0.9 per year is more reasonable than 0.375 per year (Miller et al. 2005).

Given the current focus on blue crab conservation (Lipcius et al. 2001, 2003a; Seitz et al. 2001; Lipcius and Stockhausen 2002) and the target and threshold fishing mortality rates (BBCAC 2001; Miller et al. 2005; CBSAC 2005), there is a need to obtain reliable estimates of survival to compare with these biological reference points. Tag return studies using analytical models of the Brownie type can be used to obtain robust estimates of annual survival (Brownie et al. 1985). In addition, Brownie et al. (1985) and Hearn et al. (1998) have shown that if tagging occurs more than once per year, it is possible to divide the total mortality estimates into their temporal components.

Mature female blue crabs are ideal for tag return studies because they do not molt (Churchill 1919; Van Engel 1958), so tag loss is assumed to be minimal. The shape of the carapace is such that a lightweight and noninvasive tag can easily be attached around the lateral spines on the dorsal surface. Tag return studies on the blue crab have been used to examine migration (Fischler and Walburg 1962; Turner et al. 2003; Aguilar et al. 2005; and references therein), to provide estimates of population size (Fischler 1965), and to assess the effectiveness of protected areas (Medici 2004; Lambert et al. 2006). The objective of this study was to estimate annual and semiannual survival rates of adult female blue crabs in Chesapeake Bay through tag return methods.

\section{Methods}

Tagging protocol.-Mature female crabs were captured, tagged, and released by several fisheryindependent research surveys from November 2001 to March 2005. In winter, blue crabs were tagged by the baywide winter dredge survey, Virginia Institute of Marine Science (VIMS) trawl survey, and VIMS Chesapeake Bay Multispecies Monitoring and Assessment Program (ChesMMAP) survey. In summer, blue crabs were tagged by the VIMS trawl survey, MDNR trawl survey, and VIMS ChesMMAP survey. The Chesapeake Biological Laboratory Chesapeake Bay Fishery Independent Multispecies Fisheries Survey (CHESFIMS) also tagged blue crabs in the summer of 2004. Winter tagging took place during 26 November 2001-22 February 2002 (hereafter, winter 2001), 28 October 2002-13 March 2003 (winter 2002), 28 October 2003-4 March 2004 (winter 2003), and 28 October 2004-25 February 2005 (winter 2004). Summer tagging occurred during 20 May 2002-22 August 2002 (hereafter, summer 2002), 20 May 200328 August 2003 (summer 2003), and 17 May 2004-27 August 2004 (summer 2004).

Tagging protocol was the same as described in Lambert et al. (2006). Crabs were measured (carapace width, spine tip to spine tip) with vernier calipers and tagged by tying a strap tag across the back and around the lateral spines; the ends were crimped together with a $0.635-\mathrm{cm}$, zinc-plated copper oval sleeve (mean weight of tag and crimp $\pm \mathrm{SD}=1.27 \pm 0.06 \mathrm{~g}$ ). Crabs were then released as close as possible to the capture location. Each tag had an individual identification number, a toll-free phone number, the words " $\$ 20$ Reward" (U.S. dollars), and instructions to record the location and date of capture. An informational flyer was sent in February 2004 to all licensed crab fishers in Virginia to inform them of the tagging program. Newspaper articles in the Waterman's Gazette (pub- 
lished by the Maryland Watermen's Association) also publicized the program regularly since July 2004.

Captures of tagged blue crabs were reported by commercial and recreational fishers who either left a message on the tag reporting phone line or spoke directly with staff at VIMS. We obtained as much of the following information over the phone as possible: location of capture, date of capture, water depth, method of capture, presence or absence of an egg mass, and whether the fisher was commercial or recreational. A letter describing the tagging program with the corresponding crab release information, a data sheet, a map of Chesapeake Bay, and a self-addressed stamped envelope were mailed to the fisher with instructions to make any additional comments, to mark the location of the capture, and to return the data forms and tag back to VIMS. Once the tag was received, payment was mailed to the fisher.

One caveat to the tagging procedure is that during winter 2002 the majority of the tags used (520 of 537) were labeled with "Reward" rather than "\$20 Reward." We do not think this greatly affected the recovery rate since the tagging program was 1 year old at this point, fishers were already aware of the $\$ 20$ reward, and the tag recovery rate did not differ significantly across years (see Results).

Survey design.-A brief description of the research surveys that obtained and tagged blue crabs is provided in Lambert et al. (2006). In addition to the previously described surveys, the baywide winter dredge survey is conducted annually throughout Chesapeake Bay from November to March by VIMS and MDNR. The survey uses a stratified random design that divides the Chesapeake Bay into three geographic strata: upper, middle, and lower. A Virginia crab dredge (width = $1.83 \mathrm{~m})$ lined with a plastic mesh $(1.3-\mathrm{cm}$ mesh) is towed along the bottom for $1 \mathrm{~min}$ at about $3 \mathrm{knots}$ at approximately 1,500 sites each winter (Sharov et al. 2003).

Distance traveled.-Recapture locations of tagged crabs were plotted using ArcView geographical information systems (GIS) software (ESRI, Redlands, California) based on the location description provided by the fisher. Recapture locations are approximations as specific coordinates were rarely provided. The shortest possible in-water distance between release location and recapture location was estimated using ArcView GIS software. These distances are likely underestimates of the actual distances traveled.

Survival estimation.-A Brownie-type model (Brownie et al. 1985) was used to estimate annual survival. Briefly, the rationale of tagging studies is that if two cohorts of animals are tagged (one at the start of year 1 and one at the start of year 2), then during year 2 we would expect to get equal fractions of tags returned from the two cohorts except for the fact that the first cohort has been at liberty for an extra year and has thus experienced an extra year of mortality, which reduces the number of tag returns from the first cohort. The tag return data are described within two triangular shaped matrices in terms of the observed and expected number of recaptures from each tagged cohort in each year (Table 1). The matrix of observed data is expressed as

$$
R=\left[r_{i j}\right],
$$

where $r_{i j}$ is the number of blue crabs recovered in year $j$ from crabs tagged in year $i$. The second matrix contains the expected values for the recapture of tagged individuals. The probability of recapturing a tagged individual is based on two types of parameters: an annual survival rate $(S)$ and the tag recovery rate $(f)$, which is the rate at which tagged individuals are recovered and reported. The structure of the model used to estimate these parameters will depend on the assumptions relating to the parameters. For example, under the assumption that recovery and survival rates are year specific (referred to as model 1 by Brownie et al. [1985]), the expected recaptures will be modeled as shown in Table 1. In this model, the probability of recapturing a crab in year $j$ that was tagged in year $i$ is expressed as a function of the number of crabs tagged in year $i\left(N_{i}\right)$, the tag recovery rate in year $j\left(f_{j}\right)$, and the cumulative annual survival rate through year $(j-1)$ (defined to be 1.0 for $j=i$ ).

The recaptures from each tagged cohort are viewed as a random sample from an independent multinomial distribution. The likelihood function is therefore the product of the multinomials from all the cohorts. The values of the parameters that maximize the likelihood function are then calculated and are referred to as the maximum likelihood estimates (MLEs) of the parameters.

Tagging models for annual survival estimation.Four Brownie models were fitted separately to both the winter and summer tag return data. The winter tagging data contained four tagged cohorts and 4 years of recapture, while the summer tagging data contained three tagged cohorts and 3 years of recapture. The four models and their assumptions are as follows: (1) model $S_{t}, f_{t}$, where $S$ and $f$ vary with time; (2) model $S, f_{t}$, where the survival rate is constant and the recovery rate varies over time; (3) model $S_{t}, f$, where the survival rate varies over time and the recovery rate is constant; and (4) model $S, f$, where both the survival and recovery rates are constant over time. Model $S_{t}, f_{t}$ is the most general model and allows for the most parameters, while model $S, f$ is a simpler and more restrictive model. 
TABLE 1.-Observed and expected number of tag recoveries from a Brownie model in which the parameters vary by year (model $S_{t}, f_{t}$ ); blue crabs were tagged in $I=4$ years and recovered in $J=4$ years.

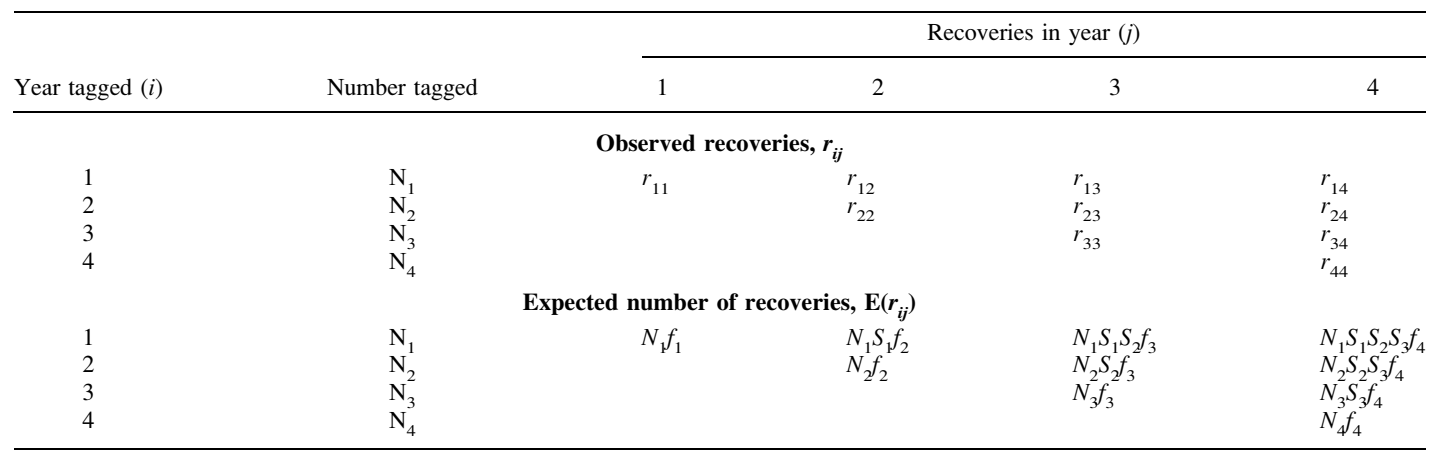

Parameter estimates were obtained for each model described above, using maximum likelihood estimation, with the software program MARK (White and Burnham 1999). Two tests were used to evaluate the models to determine the best model that properly fits the data set. A chi-square $\left(\chi^{2}\right)$ goodness-of-fit test was used first to test the null hypothesis that each model fit the data. The $\chi^{2}$ statistic was calculated by:

$$
\sum_{i, j} \frac{\left[r_{i j}-E\left(r_{i j}\right)\right]^{2}}{E\left(r_{i j}\right)}
$$

where $E$ denotes expectation of the subsequent value shown in parentheses. A calculated $\chi^{2}$-value $\left(\chi_{\text {calc }}^{2}\right)$ greater than the tabled value $\left(\chi_{\mathrm{df}, 1-\alpha}^{2}\right)$ indicates that the null hypothesis should be rejected.

Akaike's information criterion (AIC) was also used to select the most parsimonious model, which is the model that best explains the variation in the data while using the fewest parameters (Akaike 1973). The AIC values were calculated for each model by

$$
-2 \log _{e}(L)+2 p,
$$

where $L$ is the maximized likelihood of the model, and $p$ is the number of estimated parameters. Models were compared by calculating the difference in AIC values $(\triangle \mathrm{AIC})$ by

$$
\Delta \mathrm{AIC}=\mathrm{AIC}_{i}-\mathrm{AIC}_{\min },
$$

where $\mathrm{AIC}_{i}$ is the $\mathrm{AIC}$ value for model $i$, and $\mathrm{AIC}_{\text {min }}$ is the minimum AIC value over all models considered. Models that have small values $(<2)$ of $\triangle \mathrm{AIC}$ are well supported by the data (Williams et al. 2002). Among the models where $\triangle \mathrm{AIC}$ was less than 2 , the simpler, more restrictive model (the one that estimates the fewest number of parameters) was chosen for inference.

To check for overdispersion, the variance inflation factor, $\hat{c}$, was calculated in program MARK (White and Burnham 1999) by the deviance divided by its degrees of freedom. The deviance of model $j$ is defined as

$$
-2 \log _{e}\left(L_{j}\right)+2 \log _{e}\left(L_{\mathrm{sat}}\right),
$$

where $L_{j}$ is the maximum likelihood of model $j$, and $L_{\text {sat }}$ is the maximum likelihood of the saturated model (White and Burnham 1999). The saturated model is the model where each tagged cohort has a different parameter value for each recapture cell. A value of $\hat{c}$ is calculated for the most general model in a set of models under consideration, which in this study is model $S_{t}, f_{t}$. Values of $\hat{c}$ greater than 1 suggest overdispersion, which is the existence of greater variation than theoretically predicted by the multinomial sampling model and can result from a lack of independence of recapture and survival events. When overdispersion occurred (i.e., $\hat{c}>1$ ), the quasilikelihood AIC (QAIC) was calculated by:

$$
\frac{-2 \log _{e}(L)}{\hat{c}}+2 p
$$

and $\triangle$ QAIC values were calculated by $\mathrm{QAIC}_{i}-$ $\mathrm{QAIC}_{\text {min }}$, where QAIC ${ }_{i}$ is the QAIC value for model $i$, and $\mathrm{QAIC}_{\text {min }}$ is the minimum QAIC value over all models considered. The value of $\hat{c}$ was also used to inflate the SE of the parameter estimates by multiplying the SE by the square root of $\hat{c}$ (White et al. 2001).

Tagging models for semiannual survival estimation.-Semiannual estimates of survival were obtained by fitting a Brownie model analogous to model $S_{t}, f_{t}$ in Table 1 to the combined winter and summer tagging data. Tag recovery periods were specified as winter (28 October to 16 May) and summer (17 May to 27 October). Thus, there were seven tagging periods (four winter, three summer) and seven recovery periods (four winter, three summer) between October 2001 and May 2005. The four Brownie models fitted to the data were: 

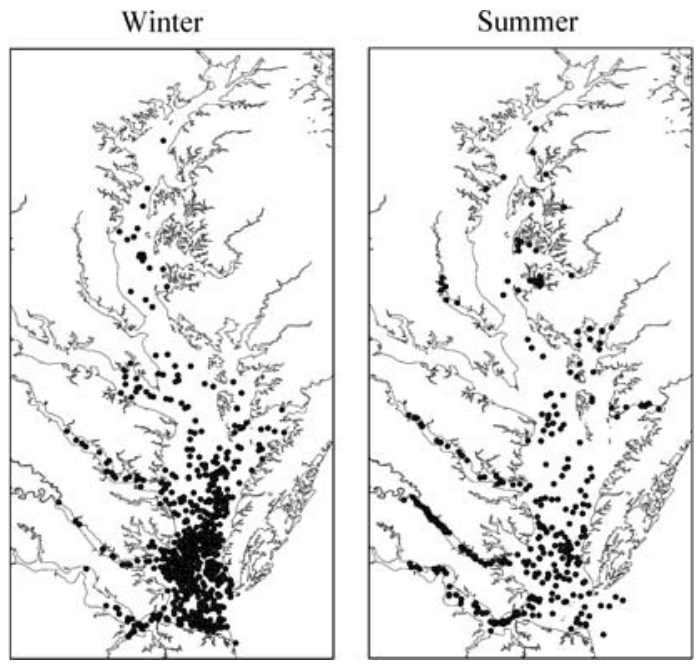

FIGURE 1.- Release locations of blue crabs tagged in the winter and summer (2001-2005 combined) in Chesapeake Bay. The dots may represent more than one crab, as multiple crabs were often released at a given location.

(1) $S_{\text {winter }, t}, S_{\text {summer }, t}, f_{\text {winter }, t}, f_{\text {summer }, t}$, where survival and recovery rates in any period (winter or summer) vary over time, (2) $S_{\text {winter }}, S_{\text {summer }}, f_{\text {winter }}, f_{\text {summer' }}$, where survival and recovery rates in any period (winter or summer) are constant over time, (3) $S_{\text {winter } t}=$ $S_{\text {summer }, t}, f_{\text {winter }, t}, f_{\text {summer }, t}$, where survival rates are constant over a year (i.e., survival rates in winter and summer of a given year are the same) and recovery rates vary over time, and (4) $S_{\text {winter }}=S_{\text {summer }}, f_{\text {winter }}$, $f_{\text {summer }}$, where survival rates are the same for all periods and recovery rates in any period (winter or summer) are constant over time. Models 3 and 4 tested the hypothesis that survival rates in winter and summer are equivalent.

Since the amount of time encompassed in the winter and summer recapture periods differed as winter rates were for $201 \mathrm{~d}$ (6.7 months) while summer rates were for $164 \mathrm{~d}$ (5.3 months), the time intervals in program
MARK (White and Burnham 1999) were set as 6.7 for the winter periods and 5.3 for the summer periods to obtain monthly estimates of survival. The estimates of tag recovery rate, $f$, obtained in program MARK (White and Burnham 1999) refer to the period (i.e., they are not monthly rates). Model fit was assessed with the $\chi^{2}$ goodness-of-fit test, and models were compared using QAIC.

Tag return assumptions.-The assumptions of this study are that (1) the tagged crabs are representative of the target population, (2) tags are not shed, (3) survival rates are not affected by tagging, (4) the year of the recovery is reported correctly, (5) the fate of each tagged crab is independent, and (6) all tagged crabs within a cohort have the same annual survival and recovery rates (Brownie et al. 1985; Pine et al. 2003). The first assumption implies that newly tagged crabs should thoroughly mix with previously tagged crabs. Nonmixing among cohorts can result from a lack of dispersal immediately after tagging. In addition, tagged crabs should mix randomly with untagged crabs and have the same catchability. To avoid violating this assumption, tagging occurred over a wide area and in proportion to the catch rate (an indicator of abundance).

\section{Results \\ General Recapture Information}

In all, 219, 537, 985, and 647 blue crabs were tagged in the winters of 2001, 2002, 2003, and 2004, respectively (Figure 1; Table 2). During winter 2002, the majority of the tags used (520 of 537) were labeled with "Reward" rather than "\$20 Reward." To determine whether this had an effect on the tag recovery rates, Brownie model $S_{t}, f_{t}$ was fitted to the data and the year-specific tag recovery rates were compared. The estimates of tag recovery rates for the first, second, third, and fourth years of the study were $27,23,25$, and $22 \%$, respectively. Since the recovery rates in all years were similar, we suspect that the labeling error did not greatly affect our estimates. Therefore, our analysis used all available tag data.

TABLE 2.-Observed tag recoveries for adult female blue crabs that were tagged during the winter. Data for cohorts winter 2001, winter 2002, winter 2003, and winter 2004 refer to crabs tagged in the following periods: 26 November 2001 to 22 February 2002, 28 October 2002 to 13 March 2003, 28 October 2003 to 4 March 2004, and 28 October 2004 to 25 February 2005 , respectively.

\begin{tabular}{|c|c|c|c|c|c|}
\hline \multirow[b]{2}{*}{ Cohort } & \multirow[b]{2}{*}{ Number tagged } & \multicolumn{4}{|c|}{ Number recovered } \\
\hline & & $\begin{array}{l}28 \text { Oct } 2001- \\
27 \text { Oct } 2002\end{array}$ & $\begin{array}{l}28 \text { Oct } 2002- \\
27 \text { Oct } 2003\end{array}$ & $\begin{array}{l}28 \text { Oct } 2003- \\
27 \text { Oct } 2004\end{array}$ & $\begin{array}{l}28 \text { Oct } 2004 \\
27 \text { Oct } 2005\end{array}$ \\
\hline Winter 2001 & 219 & 60 & 2 & 1 & 2 \\
\hline Winter 2002 & 537 & & 125 & 10 & 1 \\
\hline Winter 2003 & 985 & & & 245 & 14 \\
\hline Winter 2004 & 647 & & & & 145 \\
\hline
\end{tabular}


TABLE 3.-Observed tag recoveries for adult female blue crabs that were tagged during the summer. Data for cohorts summer 2002, summer 2003, and summer 2004 refer to crabs tagged in the following periods: 20 May 2002 to 22 August 2002, 20 May 2003 to 28 August 2003, and 17 May 2004 to 27 August 2004, respectively.

\begin{tabular}{|c|c|c|c|c|}
\hline \multirow[b]{2}{*}{ Cohort } & \multirow[b]{2}{*}{ Number tagged } & \multicolumn{3}{|c|}{ Number recovered } \\
\hline & & $\begin{array}{l}17 \text { May } 2002- \\
16 \text { May } 2003\end{array}$ & $\begin{array}{l}17 \text { May } 2003- \\
16 \text { May } 2004\end{array}$ & $\begin{array}{l}17 \text { May } 2004 \\
16 \text { May } 2005\end{array}$ \\
\hline Summer 2002 & 388 & 57 & 5 & 0 \\
\hline Summer 2003 & 343 & & 71 & 6 \\
\hline Summer 2004 & 589 & & & 100 \\
\hline
\end{tabular}

Of the 2,388 crabs tagged during the winter periods, 605 were recaptured between 28 October 2001 and 27 October 2005 (Table 2). All but six of the recaptures were reported by commercial fishers. Of the recaptures, $324(54 \%)$ were recaptured using crab pots and 262 (43\%) by crab dredge; the remainder was caught by assorted gear.

Of the 1,320 crabs tagged during the summer periods (Figure 1), 239 were recaptured between 17 May 2002 and 16 May 2005 (Table 3). The majority of the recaptures, 228 (95\%), was reported by commercial fishers. Of the recaptures, $184(77 \%)$ were recaptured using crab pots, 27 (11\%) by crab dredge, and $20(8 \%)$ by trotline; the remainder was caught by assorted gear.

The mean size of crabs (carapace width, mm) that were originally captured and subsequently tagged by trawl sampling gear (i.e., by the trawl surveys; mean \pm $\mathrm{SE}=144.5 \pm 0.3 \mathrm{~mm} ; n=2,468)$ was significantly larger (analysis of variance [ANOVA]: $F=14.07$; df $=$ $1,3641 ; P<0.0005)$ than that of the crabs originally captured by dredge gear $(142.6 \pm 0.4 \mathrm{~mm} ; n=1,175)$. However, the significant difference between sizes of trawl and dredge crabs was mostly due to the extremely large sample sizes. More importantly, the biological difference was trivial $(1.9 \mathrm{~mm} ; 142.6$ versus 144.5 $\mathrm{mm}$ ), and the amount of variation explained by the capture method was less than $1 \%$. Consequently, we conclude that the capture method should not significantly influence the tagging results.

The mean size $( \pm \mathrm{SE})$ of all females tagged was $143.9 \pm 0.2 \mathrm{~mm}(n=3,643)$. The mean size of crabs that were recaptured $(146.1 \pm 0.5 \mathrm{~mm} ; n=806)$ was significantly larger (ANOVA: $F=23.15$; df $=1,3641$; $P<0.0005)$ than the mean size of crabs that were not recaptured $(143.3 \pm 0.3 \mathrm{~mm} ; n=2,837)$. As with the gear analysis, however, this significance was also due to the extremely large sample sizes. The biological difference was also not substantial (2.8 mm; 146.1 versus $143.3 \mathrm{~mm}$ ), and the amount of variation explained by the recaptured-nonrecaptured factor was again less than $1 \%$. We thus conclude that the difference in size between recaptured and nonrecaptured crabs should not significantly influence the tagging results. We also note that it is reasonable and expected that the recaptured crabs would be slightly larger than nonrecaptured crabs due to the use of cull rings in crab traps (Lipcius and Stockhausen 2002). The distance traveled by crabs varied from less than 1 to $205 \mathrm{~km}$ (mean $\pm \mathrm{SE}=21 \pm 1 \mathrm{~km} ; n=742$ ).

\section{Annual Survival}

The goodness-of-fit test associated with all four Brownie models fitted to the winter tagging data suggested that model fit was not adequate (Table 4).

TABLE 4.-Goodness-of-fit and Akaike information criterion (AIC) results. The $\chi^{2}$ calculated value $\left(\chi_{\text {calc }}^{2}\right), \chi^{2}$ critical value $\left(\chi_{\mathrm{df}, 1-\alpha}^{2}\right)$, degrees of freedom (df), $P$-value, number of estimable parameters, and $-2 \log _{e}(L)$ are for four different Brownie models fitted to the winter and summer tagging data. For the winter tagging data, the variance inflation factor $(\hat{c})$ was 5.32 ; since $\hat{c}>1$, QAIC (quasilikelihood AIC) and $\triangle$ QAIC was calculated. For the summer tagging data, $\hat{c}<1$, therefore AIC and $\triangle$ AIC were calculated; $\mathrm{NA}=$ not applicable, meaning it was not appropriate to calculate the corresponding parameter.

\begin{tabular}{|c|c|c|c|c|c|c|c|c|c|c|c|}
\hline \multirow[b]{2}{*}{ Source } & \multirow[b]{2}{*}{ Model } & \multicolumn{4}{|c|}{ Goodness of fit } & \multirow{2}{*}{$\begin{array}{l}\text { Number of } \\
\text { parameters }\end{array}$} & \multirow[b]{2}{*}{$-2 \log _{e}(L)$} & \multirow[b]{2}{*}{ QAIC } & \multirow[b]{2}{*}{$\triangle \mathrm{QAIC}$} & \multirow[b]{2}{*}{$\mathrm{AIC}$} & \multirow[b]{2}{*}{$\Delta \mathrm{AIC}$} \\
\hline & & $\chi_{\text {calc }}^{2}$ & $\chi_{\text {critical }}^{2}$ & df & $P$ & & & & & & \\
\hline \multirow[t]{4}{*}{ Winter } & $\left(S_{t}, f_{t}\right)$ & 128.37 & 7.81 & 3 & $<0.0001$ & 7 & $2,951.36$ & 568.77 & 9.28 & NA & NA \\
\hline & $(S, f)$ & 141.37 & 11.07 & 5 & $<0.0001$ & 5 & $2,951.91$ & 564.87 & 5.38 & NA & NA \\
\hline & $\left(S_{t}, f\right)$ & 127.26 & 12.59 & 6 & $<0.0001$ & 4 & $2,954.25$ & 563.31 & 3.82 & NA & NA \\
\hline & $(S, f)$ & 145.11 & 15.51 & 8 & $<0.0001$ & 2 & $2,955.19$ & 559.49 & 0 & NA & NA \\
\hline \multirow[t]{4}{*}{ Summer } & $\left(S_{t}, f_{t}\right)$ & 0.42 & 3.84 & 1 & 0.52 & 5 & $1,320.55$ & NA & NA & $1,330.55$ & 1.32 \\
\hline & $(S, f)$ & 1.16 & 5.99 & 2 & 0.56 & 4 & $1,321.23$ & NA & NA & $1,329.23$ & 0 \\
\hline & $\left(S_{t}, f\right)$ & 5.20 & 7.81 & 3 & 0.16 & 3 & $1,325.34$ & NA & NA & $1,331.34$ & 2.11 \\
\hline & $(S, f)$ & 5.62 & 9.49 & 4 & 0.23 & 2 & $1,325.74$ & NA & NA & $1,329.74$ & 0.51 \\
\hline
\end{tabular}


TABLE 5.- Tag recoveries for a twice-a-year tagging study where tagging was conducted in the winter and summer. See Methods for the dates each cohort was tagged.

\begin{tabular}{|c|c|c|c|c|c|c|c|c|}
\hline \multirow[b]{2}{*}{ Cohort } & \multirow[b]{2}{*}{$\begin{array}{l}\text { Number } \\
\text { tagged }\end{array}$} & \multicolumn{7}{|c|}{ Number recaptured in period: } \\
\hline & & $\begin{array}{l}28 \text { Oct } 2001- \\
16 \text { May } 2002\end{array}$ & $\begin{array}{c}17 \text { May- } \\
27 \text { Oct } 2002\end{array}$ & $\begin{array}{l}28 \text { Oct } 2002- \\
16 \text { May } 2003\end{array}$ & $\begin{array}{c}17 \text { May- } \\
27 \text { Oct } 2003\end{array}$ & $\begin{array}{l}28 \text { Oct } 2003- \\
16 \text { May } 2004\end{array}$ & $\begin{array}{c}17 \text { May- } \\
27 \text { Oct } 2004\end{array}$ & $\begin{array}{l}28 \text { Oct } 2004 \\
16 \text { May } 2005\end{array}$ \\
\hline Winter 2001 & 219 & 54 & 6 & 2 & 0 & 1 & 0 & 1 \\
\hline Summer 2002 & 388 & & 50 & 7 & 2 & 3 & 0 & 0 \\
\hline Winter 2002 & 537 & & & 88 & 37 & 7 & 3 & 1 \\
\hline Summer 2003 & 343 & & & & 51 & 20 & 4 & 2 \\
\hline Winter 2003 & 985 & & & & & 199 & 46 & 14 \\
\hline Summer 2004 & 589 & & & & & & 76 & 24 \\
\hline Winter 2004 & 647 & & & & & & & 112 \\
\hline
\end{tabular}

The poor fit was due to the recapture of two tagged crabs in year 4 that were tagged in year 1 (cell $r_{14}$ in the observed data matrix). If those two recaptures are eliminated from the analysis (i.e., the $r_{14}$ cell is changed from a 2 to a 0$)$, all models would fit the data $\left(\chi_{\text {calc }}^{2}<\right.$ $\chi_{\text {critical }}^{2}$ for all models) and the calculated $\hat{c}$ value would be less than 1. Model $S, f$ would have the lowest AIC value, and $\hat{S}$ would be $0.068 \pm 0.012$ (95\% confidence interval [CI]: 0.048-0.097). Although the probability of surviving the 3 years between years 1 and 4 is very low, it is still possible; therefore, we decided to keep those recaptures in the analysis. Due to poor model fit, variance inflation factor was calculated by:

$$
\begin{aligned}
\hat{c} & =\frac{-2 \log _{e}(L)_{S_{t}, f_{t}}+2 \log _{e}(L)_{\text {sat }}}{\mathrm{df}} \\
& =\frac{2,951.36-2,935.40}{3}=5.32,
\end{aligned}
$$

and was used to calculate QAIC and $\triangle$ QAIC values and to adjust the SEs associated with parameter estimates. Model fit was adequate for all four Brownie models fitted to the summer tagging data (Table 4). Because the calculated $\hat{c}$ value was less than 1 , AIC and $\triangle \mathrm{AIC}$ values were calculated.

For the winter tagging data, model $S, f$ had the lowest $\triangle$ QAIC value (Table 4) and was thus selected for inference. For the summer tagging data, three of the four models had $\triangle \mathrm{AIC}$ values less than 2.0 (Table 4). Therefore, model $S, f$ was selected for inference because this model estimates the least number of parameters. Estimates of annual survival using model $S, f$ derived from both the winter and summer tagging data were nearly identical (winter data: $\hat{S} \pm \mathrm{SE}=0.081$ $\pm 0.031,95 \% \mathrm{CI}=0.038-0.166$; summer data: $\hat{S} \pm$ $\mathrm{SE}=0.080 \pm 0.024,95 \% \mathrm{CI}=0.044-0.140) . \mathrm{Tag}$ recovery rate $(f \pm \mathrm{SE})$ was estimated to be $0.239 \pm$ $0.020(95 \% \mathrm{CI}=0.202-0.280)$ and $0.173 \pm 0.010$ (95\% CI $=0.154-0.194)$ based on the winter and summer tagging data, respectively.

\section{Semiannual Survival}

The goodness-of-fit test associated with the four Brownie models fitted to the twice-per-year tagging data (Table 5) suggested that the model fit was not adequate (Table 6). The poor fit was due to the recapture of one tagged crab in period 7 , which was tagged in year 1 . If that one recapture is eliminated from the analysis (i.e., the $r_{17}$ cell in the observed data matrix is changed from a 1 to a 0 ), then model 1 would fit the data (i.e., $\chi_{\text {calc }}^{2}<\chi_{\text {critical }}^{2}$ ) but models $2-4$ would not. The calculated $\hat{c}$ value would be 1.03 , and the model with the lowest QAIC value would be model $S_{\text {winter }, t}, S_{\text {summer }, t}, f_{\text {winter }, t}, f_{\text {summer }, t}$. Although the

TABLE 6.-Goodness-of-fit and Akaike information criterion (AIC) results for the twice-a-year tagging data. The calculated variance inflation factor $(\hat{c}=1.54)$ was greater than 1 , indicating overdispersion. Therefore, QAIC and $\Delta$ QAIC were calculated to

\begin{tabular}{|c|c|c|c|c|c|c|c|c|}
\hline \multirow[b]{2}{*}{ Model } & \multicolumn{4}{|c|}{ Goodness of fit } & \multirow[b]{2}{*}{ Number of parameters } & \multirow[b]{2}{*}{$-2 \log _{e}(L)$} & \multirow[b]{2}{*}{ QAIC } & \multirow[b]{2}{*}{$\Delta \mathrm{QAIC}$} \\
\hline & $\chi_{\text {calc }}^{2}$ & $\chi_{\text {critical }}^{2}$ & df & $p$ & & & & \\
\hline $1: S_{\text {winter }, t}, S_{\text {summer } t}, f_{\text {winter } t}, f_{\text {summer } t}$ & 76.99 & 19.68 & 11 & $<0.0001$ & 13 & $4,858.65$ & $3,180.97$ & 3.66 \\
\hline 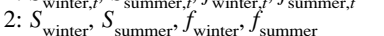 & 72.03 & 31.41 & 20 & $<0.0001$ & 4 & $4,880.73$ & $3,177.31$ & 0 \\
\hline 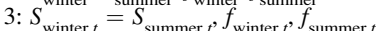 & 112.31 & 23.69 & 14 & $<0.0001$ & 10 & $4,876.15$ & $3,186.33$ & 9.02 \\
\hline 4: $S_{\text {winter }, t}^{\text {winter }}=S_{\text {summer }}, f_{\text {winter }}, f_{\text {summer }}^{\text {summer } t}$ & 94.99 & 32.67 & 21 & $<0.0001$ & 3 & $4,906.57$ & $3,228.08$ & 50.77 \\
\hline
\end{tabular}
account for the lack of model fit. 
probability of surviving more than 3 years between being tagged in year 1 and recaptured in period 7 is very low, it is still possible; therefore, we decided to keep the recapture in the analysis. Due to the poor model fit, variance inflation factor was calculated by:

$$
\begin{aligned}
\hat{c} & =\frac{-2 \log _{e}\left(L_{\left.S_{\text {winter }, t}, S_{\text {summer }, t}, f_{\text {winter }, t}, f_{\text {summer }, t}\right)+2 \log _{e}(L)_{\text {sat }}}^{\mathrm{df}}\right.}{} \\
& =\frac{4,861.78-4,844.82}{11}=1.54
\end{aligned}
$$

and was used to calculate QAIC and $\triangle$ QAIC values and to adjust the SEs associated with parameter estimates.

Models $S_{\text {winter }, t}=S_{\text {summer }, t}, f_{\text {winter }, t}, f_{\text {summer }, t}$ and $S_{\text {winter }}=S_{\text {summer }}, f_{\text {winter }}, f_{\text {summer }}$ had high $\Delta$ QAIC values (Table 6), suggesting that survival rates in winter and summer were not equivalent. Model $S_{\text {winter }}, S_{\text {summer' }}$, $f_{\text {winter }}, f_{\text {summer }}$ had the lowest QAIC value and was thus chosen for inference. Estimated monthly rates $( \pm S E)$ of survival during the winter period (28 October to 16 May) were $0.868 \pm 0.016(95 \% \mathrm{CI}=0.832-0.897)$, while monthly rates of survival during the summer period (17 May to 27 October) were estimated to be $0.748 \pm 0.019(95 \% \mathrm{CI}=0.708-0.783)$. Given that the amount of time encompassed in the winter $(6.7$ months) and summer (5.3 months) periods differed, these monthly rates could be converted into period rates by $\left(\hat{S}_{\text {winter }}\right)^{6.7}$ and $\left(\hat{S}_{\text {summer }}\right)^{5.3}$, respectively. The estimated rate of survival $( \pm \mathrm{SE})$ over the winter period was $0.387 \pm 0.048$, while the estimated rate over the summer period was $0.215 \pm 0.029$. In addition, an annual survival rate was estimated by the product of the two semiannual rates $\left(\hat{S}=\hat{S}_{\text {winter }} \times \hat{S}_{\text {summer }}=0.387 \times\right.$ $0.215=0.083 \pm 0.045)$. This estimate of annual survival is statistically equivalent to the estimates ( $\pm \mathrm{SE}$ ) derived from the separate winter and summer (once-per-year) models, which were $0.081 \pm 0.031$ and $0.080 \pm 0.024$, respectively. The estimated tag recovery rate $( \pm \mathrm{SE})$ for the winter period was $0.188 \pm$ $0.010(95 \% \mathrm{CI}=0.170-0.209)$, while the estimated tag recovery rate for the summer period was $0.132 \pm$ $0.011(95 \% \mathrm{CI}=0.112-0.155)$.

\section{Tag Retention}

To determine if tags remain intact when exposed to brackish water over the long term, 24 tags were attached to bricks and placed in the York River, Virginia, in March 2004 and were routinely checked. All tags were retained after 2.25 years of exposure to brackish water (salinity $=20-22 \%$ ).

\section{Discussion}

The two independent estimates $( \pm \mathrm{SE}$ ) of survival based on winter tagging $(0.081 \pm 0.031)$ and summer tagging $(0.080 \pm 0.024)$ were virtually identical and very low. These estimates were also similar to our estimates based on the product of two semiannual estimates of survival $(0.083 \pm 0.045)$. The question is whether such a low survival is credible and consistent with other data. Note first that we had excellent cooperation from the fishers as evidenced by the high tag recovery rate (between $22 \%$ and $27 \%$ ) during each of the 4 years of the study. Previous studies obtained overall recovery rates of 6-12\% (Fiedler 1930; McConaugha 1991; Turner et al. 2003; Aguilar et al. 2005) for similar tags used on blue crabs in Chesapeake Bay. Therefore, the low number of returns from cohort 1 in years $2-4$; from cohort 2 in years 3 and 4; and from cohort 3 in year 4 was not due to lack of cooperation in years $2-4$.

In addition, one might question whether a significant fraction of the tagged blue crabs might have emigrated outside Chesapeake Bay which, if progressive over time, would cause survival rate to be underestimated. However, a concurrent field investigation of crab abundance inside and outside Chesapeake Bay between January and March 2003 demonstrated that a very small proportion of the blue crab population resided outside of the bay proper (Lipcius et al. 2003b). While tagging studies have documented a few cases where adult blue crabs have emigrated outside of Chesapeake Bay (Cronin 1949; McConaugha 1991; Aguilar et al. 2005), it is generally considered that adult blue crabs limit their movements to within an estuary (Fischler and Walburg 1962; Judy and Dudley 1970). The tagged crabs did, however, move a great deal throughout Chesapeake Bay during their time at liberty as the mean distance traveled was $21 \mathrm{~km}$, suggesting that they did mix with nontagged crabs (an important assumption of tagging studies). Thus, we believe that our estimates for survival rate were not biased significantly by statistical, biological, or environmental conditions. In addition, we believe our results were not biased by tag loss as all tags that were attached to bricks remained intact after long-term exposure $(>2.25$ years) to brackish water.

The goodness-of-fit tests associated with all four Brownie models fitted to the winter tagging data (Table 4 ) and with the four models fitted to the twice-per-year tagging data (Table 6) suggested that the model fit was not adequate. The poor fit was due to the recapture of one or two animals in year 4 that were tagged in year 1 . This is common in tag return data, as values in the rightmost cells in the matrix of expected values are often very small. Although the probability of surviving the 3 years between years 1 and 4 is very low, it is still possible. Analysis was conducted despite the lack of model fit and the variance inflation factor, $\hat{c}$, was used 
to adjust SEs associated with parameter estimates to account for the lack of fit.

Model $S, f$ was selected for inference for both the summer and winter tagging data. However, we do not conclude that survival rates have remained constant over time. Model selection was based solely on $\triangle \mathrm{AIC}$ or $\triangle \mathrm{QAIC}$ values. Formal model selection procedures aim to find the most parsimonious model (i.e., the model that best explains the variation in the data while using the fewest parameters). The observed variability in survival estimates is explainable by sampling error, so the evidence for time varying survival is not compelling in our data. This, however, does not mean that survival is necessarily constant over time for the whole population.

Ideally, all tag releases for a cohort would have occurred within a short time period. Since this was not logistically possible, the releases occurred over a longer time "window." This introduces some bias since crabs that are released first will experience more fishing and natural mortality than those released later. For example, the winter tagging occurred between late October and March. Crabs released towards the end of the winter would have less of a chance to be recaptured during the first year simply because they are at large for a shorter time period. If the probability of being recaptured in the first year of tag recovery is reduced as the time window of releases increases, the survival rates will be overestimated. The bias, however, may not be substantial since the majority of the tagging in winter occurred early in the winter season.

Our low estimates of survival are consistent with historical studies showing that only a small percentage of adult female blue crab captured in the winter had spawned previously. Newcombe (1945) examined the ovary condition of adult females from the lower bay and found that only $6 \%$ had spawned before. Similarly, Hopkins (1947) determined that only $7 \%$ of adult females from Virginia waters showed evidence of previous spawning as indicated by the appearance of egg remnants, exhausted ovaries, and condition of nemertean infestation (an indicator of previous spawning). Williams and Porter (1964) examined female blue crabs from Delaware Bay in 1954 and found that only $6 \%$ had spawned previously based on ovary condition and nemertean infestation. Since blue crab females spawn annually after reaching maturity, these studies suggest that mortality was relatively high and that few females survived longer than 2 years. This appears to be the case under current levels of exploitation as Ju et al. (2003) found that very few blue crabs in Chesapeake Bay were more than 2 years old.

The maximum age of blue crabs, although not known precisely, is relatively short, which further supports a low annual survival rate. Tag return data has provided evidence that blue crabs can live as long as 4 years in St. John's River, Florida (Tagatz 1968), 5 years in North Carolina (Fischler 1965), and 8 years in Chesapeake Bay (Rugolo et al. 1998). Various values for maximum age have been used in blue crab stock assessments, including 3 years for the Delaware Bay stock (Kahn and Helser 2005); 3, 5, and 8 years for the North Carolina stock (Eggleston et al. 2004); 3 and 6 years for stocks in Florida (Murphy et al. 2001); and 8 years for the Chesapeake Bay stock (Rugolo et al. 1998). In our tagging study, we recovered one tag (Tag A00145) in December 2004, almost 3 years after the crab was released in January 2002. Given that this individual was from 1 to over 2 years old at tagging (age at maturity depends upon whether maturation occurs in the northern or southern portions of the bay; Van Engel 1958), this crab is estimated to have lived for at least 4 and possibly 5 years.

Our estimates of annual survival are much lower than what was once thought in past stock assessments (Rugolo et al. 1998). Using an assumed natural mortality rate of 0.375 per year (as used by Rugolo et al. 1998) and the female-specific exploitation rate estimates from 2002 and 2003 (0.64, 0.55, respectively; Miller et al. 2005) to solve for $F$ using methods described in Sharov et al. (2003), the estimates of survival $\left(S=e^{-[0.375+F]}\right)$ for 2002 and 2003 are 0.18 and 0.25 , respectively. There are several important issues to consider when comparing these results of survival $(18-25 \%)$ with the results from the present study ( $\sim 8 \%$ survival). First, the results based on the exploitation rate method (Sharov et al. 2003) do not account for recreational landings of blue crabs and thus $u$ may be biased low, resulting in an underestimate of $F$ and an overestimate of $S$; our tagging results include all sources of mortality. Secondly, our estimates of survival are only for adult females, while the exploitation rate is based on the abundance of all female crabs that are legal size or are going to achieve legal size during the year. Thirdly, the estimates of $u$ are for the years 2002 and 2003, while our estimates of survival are for the time period 28 October 2001-27 October 2002 and 28 October 2002-27 October 2003. While the timing relating to the two parameters is not the same, it is relatively close. Most importantly, Rugolo et al. (1998) and Sharov et al. (2003) assumed a value of 0.375 per year for $M$, whereas the tagging estimates of survival do not depend on knowledge of $M$. Results from the recent stock assessment suggest that a more likely value for natural mortality is 0.9 per year (Miller et al. 2005). Therefore, using an $M$ of 0.9 per year and using the same methods described above to estimate $F$ from the exploitation rate, the estimates 
of survival $\left(S=e^{-[0.9+F]}\right)$ for adult females for 2002 and 2003 are 0.06 and 0.10 , respectively. Taggingbased estimates of survival are thus similar to estimates derived from the exploitation rate method when the assumed value of $M$ is 0.9 per year. Although taggingbased estimates of $S$ are not strictly comparable to those based on the exploitation rate method (Sharov et al. 2003), both indicate that survival was extremely low in recent years and much lower than that estimated by Rugolo et al. (1998; using a length-based method). It would be ideal to compare estimates of exploitation rate with tag-based estimates of survival over several years to determine if changes in one are tracked by changes in the other. If it were found that the estimates tracked each other, then this would serve as a form of validation of tag-based estimates of survival and dredge survey-derived estimates of exploitation.

The estimated monthly rate of survival during the winter $(\hat{S}=0.868)$ was much higher than the estimated monthly rate of survival during the summer $(\hat{S}=0.748)$, which could reflect trends in exploitation or seasonal changes in natural mortality rate. Similarly, the annual tag recovery rate obtained from the Brownie model fitted to the winter tagging data $(\hat{f}=0.24)$ was higher than the annual tag recovery rate from the Brownie model fitted to the summer tagging data $(\hat{f}=0.17)$. The relatively lower recovery rates obtained from summer data could reflect tag-induced mortality in the summer months. Crabs tagged in the summer were often exposed to extremely hot air temperatures (range $=27-38^{\circ} \mathrm{C}$ ) during tagging, which could increase the probability of dying immediately after tagging. Provided that tagginginduced mortality is consistent from summer to summer, this does not bias the estimates of survival.

Tag return methodology has proven to be an effective means of estimating the annual and semiannual rates of survival for adult female blue crabs. This study provides the only known experimentally derived estimate of survival for the blue crab. Other estimates of survival use length-based methods or methods that are heavily dependent on an assumed $M$. In addition, this study provides the only known use of a Brownie model to estimate semiannual survival rates for an invertebrate species subject to a continuous fishery. Finally, the two independent estimates of annual survival based on winter and summer tagging were essentially the same and low. Consequently, low survival rates of mature female blue crabs in Chesapeake Bay during a period of depressed abundance may be preventing stock recovery.

\section{Acknowledgments}

We are extremely grateful to the following research surveys for their assistance in tagging of blue crabs:
VIMS trawl survey, MDNR trawl survey, ChesMMAP, CHESFIMS, and the baywide winter dredge survey. We would specifically like to thank N. Olmstead, K. Knick, K. Erickson, M. Montane, W. Lowry, L. Liguori, T. Mathes, C. Crippen, A. Halvorson, H. Brooks, P. Gerdes, J. Ellis, M. Hewitt, A. Jestel, E. Sherry, J. Gartland, E. Brasseur, P. Lynch, C. Bonzek, R. Latour, D. Ward, J. Gibbs, L. Fegley, G. Davis, and T. Miller. We are grateful to M. Seebo for developing the tagging system and overseeing much of the tagging effort, D. Wilcox for assistance with GIS software, L. Fegley for providing sex-specific estimates of exploitation rates, and D. Kahn for pointing out several important references on blue crab mortality. D. Hewitt, R. Latour, and R. Chuenpagdee provided helpful comments on the manuscript. Funding was provided by the National Oceanic and Atmospheric Administration Chesapeake Bay Office under two projects; most research was funded under the project "Tagging Studies of Blue Crabs in Chesapeake Bay," while analyses and report preparation were funded by the project "Blue Crab Advanced Research Consortium." This is contribution number 2752 of VIMS, The College of William and Mary.

\section{References}

Aguilar, R., A. H. Hines, T. G. Wolcott, D. L. Wolcott, M. A. Kramer, and R. N. Lipcius. 2005. The timing and route of movement and migration of post-copulatory female blue crabs, Callinectes sapidus Rathbun, from the upper Chesapeake Bay. Journal of Experimental Marine Biology and Ecology 319:117-128.

Akaike, H. 1973. Information theory as an extension of the maximum likelihood principle. Pages 1-24 in B. N. Petrov and F. Csaki, editors. Second International Symposium on Information Theory. Akademiai Kiado, Budapest, Hungary.

BBCAC (Bi-State Blue Crab Advisory Committee). 2001. Taking action for the blue crab: managing and protecting the stock and its fisheries. Chesapeake Bay Commission, BBCAC Report, Annapolis, Maryland. Available: http:// www.chesbay.state.va.us/crabPubs.htm (May 2004).

Brownie, C., D. R. Anderson, K. P. Burnham, and D. S. Robson. 1985. Statistical inference from band recovery data: a handbook, 2nd edition. U.S. Fish and Wildlife Service, Resource Publication 156, Washington, D.C. Available: http://www.warnercnr. colostate.edu/ class_info/fw663/Brownie1985/BrownieList.html (May 2004).

CBSAC (Chesapeake Bay Stock Assessment Committee). 2005. 2005 Chesapeake Bay blue crab advisory report. NOAA, Advisory Report, Annapolis, Maryland. Available: http://noaa.chesapeakebay.net (September 2005).

Churchill, E. P., Jr. 1919. Life history of the blue crab. U.S. Bureau of Fisheries Bulletin 36:91-134.

Cronin, L. E. 1949. Comparison of methods of tagging the blue crab. Ecology 30:390-394.

Eggleston, D. B., E. G. Johnson, and J. Hightower. 2004. 
Population dynamics and stock assessment of the blue crab in North Carolina. Final Report for Contract 99FEG-10 and 00-FEG-11 of North Carolina State University to the North Carolina Fishery Research Grant Program, North Carolina Sea Grant, and the North Carolina Department of Environmental Health and Natural Resources, Division of Marine Fisheries, Raleigh. Available: http://www.ncseagrant.org (May 2005).

Fiedler, R. 1930. Solving the question of crab migrations. Fishing Gazette 47:18-21.

Fischler, K. J. 1965. The use of catch-effort, catch-sampling, and tagging data to estimate a population of blue crabs. Transactions of the American Fisheries Society 94:287310.

Fischler, K. J., and C. H. Walburg. 1962. Blue crab movement in coastal South Carolina, 1958-59. Transactions of the American Fisheries Society 91:275-278.

Hearn, W. S., K. H. Pollock, and E. N. Brooks. 1998. Pre- and post-season tagging models: estimation of reporting rate and fishing and natural mortality rates. Canadian Journal of Fisheries and Aquatic Sciences 55:199-205.

Hopkins, S. H. 1947. The nemertean Carcinonemertes as an indicator of the spawning history of the host, Callinectes sapidus. Journal of Parasitology 33:146-150.

Ju, S.-J., D. H. Secor, and H. R. Harvey. 2003. Demographic assessment of the blue crab (Callinectes sapidus) in Chesapeake Bay using extractable lipofuscins as age markers. Fishery Bulletin 101:312-320.

Judy, M. H., and D. L. Dudley. 1970. Movements of tagged blue crabs in North Carolina waters. Commercial Fisheries Review 32(11):29-35.

Kahn, D. M., and T. E. Helser. 2005. Abundance, dynamics and mortality rates of the Delaware Bay stock of blue crabs, Callinectes sapidus. Journal of Shellfish Research 24:269-284.

Lambert, D. M., R. N. Lipcius, and J. M. Hoenig. 2006 Assessing effectiveness of the blue crab spawning stock sanctuary in Chesapeake Bay using tag-return methodology. Marine Ecology Progress Series.

Lipcius, R. N., J. M. Hoenig, and J. F. Walter. 2003b. Spatial distribution of the blue crab in the lower Chesapeake Bay-Continental Shelf system. Report of Virginia Institute of Marine Science to Army Corps of Engineers, Norfolk.

Lipcius, R. N., R. D. Seitz, W. J. Goldsborough, M. M. Montane, and W. T. Stockhausen. 2001. A deep-water dispersal corridor for adult female blue crabs in Chesapeake Bay. Pages 643-666 in G. H. Kruse, N. Bez, A. Booth, M. W. Dorn, S. Hills, R. N. Lipcius, D. Pelletier, C. Roy, S. J. Smith, and D. Witherell, editors. Spatial processes and management of marine populations. University of Alaska Sea Grant, AK-SG-01-02, Fairbanks.

Lipcius, R. N., and W. T. Stockhausen. 2002. Concurrent decline of the spawning stock, recruitment, larval abundance, and size of the blue crab Callinectes sapidus in Chesapeake Bay. Marine Ecology Progress Series 226:45-61

Lipcius, R. N., W. T. Stockhausen, R. D. Seitz, and P. J. Geer. 2003a. Spatial dynamics and value of a marine protected area and corridor for the blue crab spawning stock in Chesapeake Bay. Bulletin of Marine Science 72:453-469.
McConaugha, J. R. 1991. Tag-recapture study of the spawning stock of Chesapeake Bay blue crabs. NOAA Technical Report NMFS91-1.

Medici, D. A. 2004. Scale dependent movements and protection of the female blue crab, Callinectes sapidus Master's thesis. North Carolina State University, Raleigh. Available: http://www.lib.ncsu.edu/etd/ (May 2005).

Miller, T. J., S. J. D. Martell, D. B. Bunnell, G. Davis, L. Fegley, A. Sharov, C. Bonzek, D. Hewitt, J. Hoenig, and R. N. Lipcius. 2005. Stock assessment of the blue crab in Chesapeake Bay 2005. Technical report series number TS-487-05 of the University of Maryland Center for Environmental Science to the National Oceanic and Atmospheric Administration, Chesapeake Bay Office, Annapolis, Maryland. Available: http://hjort.cbl.umces. edu/crabs/Assessment05.html (November 2005).

Murphy, M. D., C. A. Meyer, and A. L. McMillen-Jackson. 2001. A stock assessment for blue crab, Callinectes sapidus, in Florida waters. Florida Fish and Wildlife Conservation Commission, Florida Marine Research Institute, In-house Report Series IHR 2001-008, St. Petersburg. Available: http://www.floridamarine.org/ publications/ (May 2005).

Newcombe, C. L. 1945. 1944-1945 Report of the Virginia Fisheries Laboratory. In 46th and 47th annual reports of the Commission of Fisheries of Virginia for the fiscal years ending June 30, 1944 and June 30, 1945, to the General Assembly of Virginia, Richmond.

Pine, W. E., K. H. Pollock, J. E. Hightower, T. J. Kwak, and J. A. Rice. 2003. A review of tagging methods for estimating fish population size and components of mortality. Fisheries 28(10):10-23.

Rugolo, L. J., K. S. Knotts, A. M. Lange, and V. A. Crecco. 1998. Stock assessment of Chesapeake Bay blue crab (Callinectes sapidus Rathbun). Journal of Shellfish Research 17:493-517.

Seitz, R. D., R. N. Lipcius, W. T. Stockhausen, and M. M. Montane. 2001. Efficacy of blue crab spawning sanctuaries in Chesapeake Bay. Pages 607-626 in G. H. Kruse, N. Bez, A. Booth, M. W. Dorn, S. Hills, R. N. Lipcius, D. Pelletier, C. Roy, S. J. Smith, and D. Witherell, editors. Spatial processes and management of marine populations. University of Alaska Sea Grant, AK-SG01-02, Fairbanks.

Sharov, A. F., J. H. Volstad, G. R. Davis, B. K. Davis, R. N. Lipcius, and M. M. Montane. 2003. Abundance and exploitation rate of the blue crab (Callinectes sapidus) in Chesapeake Bay. Bulletin of Marine Science 72:543-565.

Tagatz, M. E. 1968. Biology of the blue crab, Callinectes sapidus Rathbun, in the St. Johns River, Florida. Fisheries Bulletin 67:17-33.

Turner, H. V., D. L. Wolcott, T. G. Wolcott, and A. H. Hines. 2003. Post-mating behavior, intramolt growth, and onset of migration to Chesapeake Bay spawning grounds by adult female blue crabs, Callinectes sapidus Rathbun. Journal of Experimental Marine Biology and Ecology 295:107-130.

Van Engel, W. A. 1958. The blue crab and its fishery in Chesapeake Bay. Part 1: reproduction, early development, growth, and migration. Commercial Fisheries Review 20(6):6-17.

White, G. C., and K. P. Burnham. 1999. Program MARK: 
survival estimation from populations of marked animals. Bird Study 46(Supplement):120-138.

White, G. C., K. P. Burnham, and D. R. Anderson. 2001. Advanced features of program MARK. Pages 368-377 in R. Field, R. J. Warren, H. Okarma, and P. R. Sievert, editors. Wildlife, land, and people: priorities for the 21st century. Proceedings of the second international wildlife management congress. The Wildlife Society, Bethesda,
Maryland. Available: http://www.cnr.colostate.edu/ $\sim$ gwhite/mark/mark.htm (October 2005).

Williams, A. B., and H. J. Porter. 1964. An unusually large turtle barnacle (Chelonibia p. patula) on a blue crab from Delaware Bay. Chesapeake Science 5:150-151.

Williams, B. K., J. D. Nichols, and M. J. Conroy. 2002. Analysis and management of animal populations: modeling, estimation, and decision making. Academic Press, San Diego, California. 